\title{
MINIMINING THE ENERGY SPREAD WITHIN A SINGLE BUNCH BY SHAPING ITS CHARGE DISTRIBUTION*
}

\author{
Gibgony A. LOEW and JUWEN Wang: \\ Stanford Linear Aecelerator C'enter \\ Slanford Unitersity, Stanford, California 94805
}

\section{Introduction}

When electrons or pasitrons in a bunch pass through the periodic structure of a linear accolerator, they leave behind them energy in the form of longiludinal wake ficlds. The longitudinal fields left behind by early particles in a buach decreaset the energy of later particleg. For a linear collider, the energy spread introduced within the Innches by this beam loading effect must be minimized beeause it limits the degree to which the particles can be focused to a small spot dun to chromatic effects in the final focus system. For example, for the SLC, the allowable energy spread is $\pm 0.5 \%$.

It has been known for some time that partial compensation of the longitudinal wake ficld effects can be obtained for any bunch by placing it ahead of the aceelerating crost (in space), thereby letting the positive rising sinusoidal field offset the negative heam loading feld. ${ }^{1}$ The work presented in this report shows that it is possible to ubtain complete compensation, i.e., to reduce the energy sprend esseatially to zero by properly shaping the longitudinal charge distribution of the bunch and by placing it at the correct position on the wave.

\section{Optimistng the Bunch Shape}

The energy gained by a single particle riding at an angle $\theta_{1}$ with respect to the crest of a traveling wave of accelerating gradient $E_{0}$ over a length $L$ is

$$
V=E_{0} L \cos \theta_{1}
$$

\footnotetext{
"Work supported by the Department of Energy, contract DE-AC03-76SF00515. tActurlly, if one waits long enough, the wake felds change sign and produce acceleration.

There may also be measurements of particle resonances which would benefit from extremely aarrotw cnergy spreads.
} 
In the case of a bunck consisting of many particles, this energy is modified by the prusince of the wake fields left by particles ahead of $O_{1}$. For the examples worked out in this toport, we will use the SLAC constant-gradient structure although the technique should be applicable to any strueture for which the longitudial wake fuaction is known. Thi; wake function, $w_{\mathcal{L}}(\theta)$, is defined as the voltage excited by a unil charce traversing the strusture. It is shown in Fig. 1 as calculated for a sing!e average eavity of lengtb $d / d=3.5 \mathrm{ciu}$; of the SLAC structure, To obtain the function $W_{L}$ for the entire accelerator, one simply has to multiply $w_{t}(\theta)$ by $N$, the numbor of cavities $(L / d)$. With these definitions and a hunch charge distribution $f\left(f^{\prime}\right)$ as illustrated in Fig. 2, Eq. (I) now becomes:

$$
V\left(\theta_{1}\right)=V_{0} \cos \theta_{1}-\int_{0}^{\left(b_{-}-n_{1}\right)} f\left(\theta^{\prime}\right) w_{L}\left(\theta_{0}-\theta_{1}-\theta^{\prime}\right) d \theta^{\prime} .
$$

where $V_{0}=E_{0} L_{0} Q_{0}$ is the position of the head of the bunch with respect to the ware and $d$, the noordinate within the bunch, is made to vary from 0 (the head of the buneb) to $\theta_{0}-\theta_{1}$ (the position where we want to know the net energy).

In order io reduce the epergy spread witbin the bunch to zero, we must muke $V\left(f_{1}\right)$ independent of $\theta_{1}$. This requires that

$$
\frac{\partial V\left(\theta_{2}\right)}{\partial \partial_{1}}=0 \text {. }
$$

By taking the partial derivative of $\mathrm{E}_{\mathrm{q}}$. (2) with respect to $\theta_{1}$ and setting it to 2eto, wo get:

$$
-V_{0} \sin \theta_{1}-\int_{0}^{\left(\theta_{0}-\theta_{1}\right)} \mu\left(\theta^{\prime}\right) \frac{\partial W_{L}}{\partial \theta_{1}}\left(\theta_{0}-\theta_{1}-\theta^{\prime}\right) d \theta^{\prime}+f\left(\theta_{0}-\theta_{1}\right) W_{L}(0)=0
$$

or

$$
f\left(\theta_{0}-\theta_{l}\right)=\frac{V_{0}}{W_{T}(0)} \sin \theta_{1} \quad \int_{0}^{\left(\theta_{0}-\theta_{1}\right)} \frac{f\left(\theta^{\prime}\right) \frac{\partial W_{L}}{\partial_{1}}\left(\theta_{0}-\theta_{1}-\theta^{\prime}\right)}{W_{l}(0)} d \gamma .
$$

l.rtinf a. $\eta_{1}=x$ where $x \geq \theta$, Eq. (4) becomes:

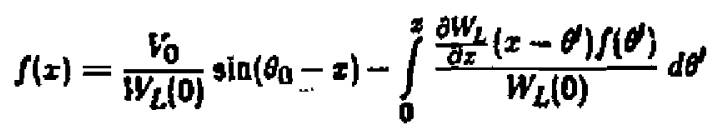




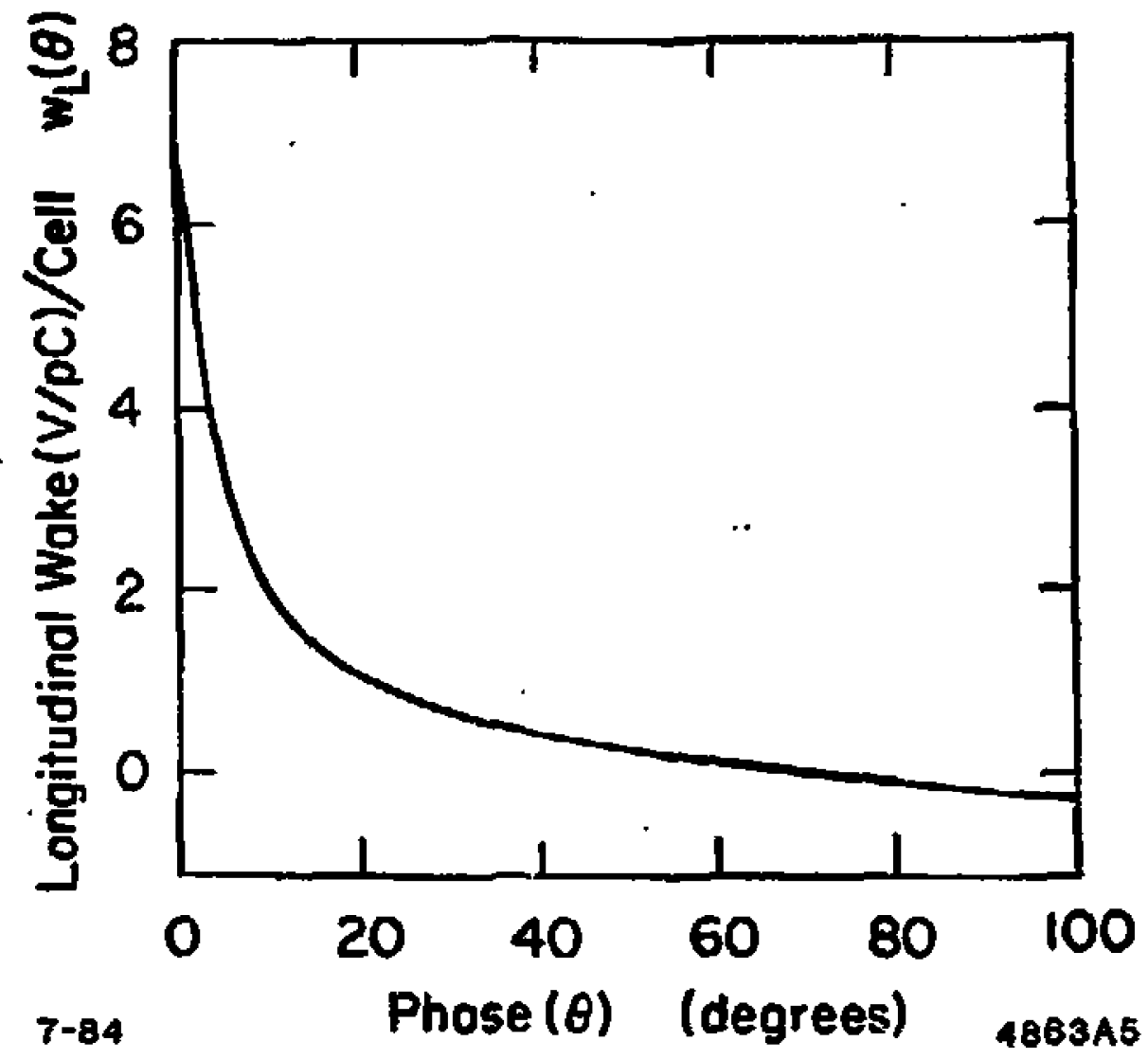

Fig. 1. Longitudinal wake function as a function of phase angle for SLAC constant- 8 sdient structure. 


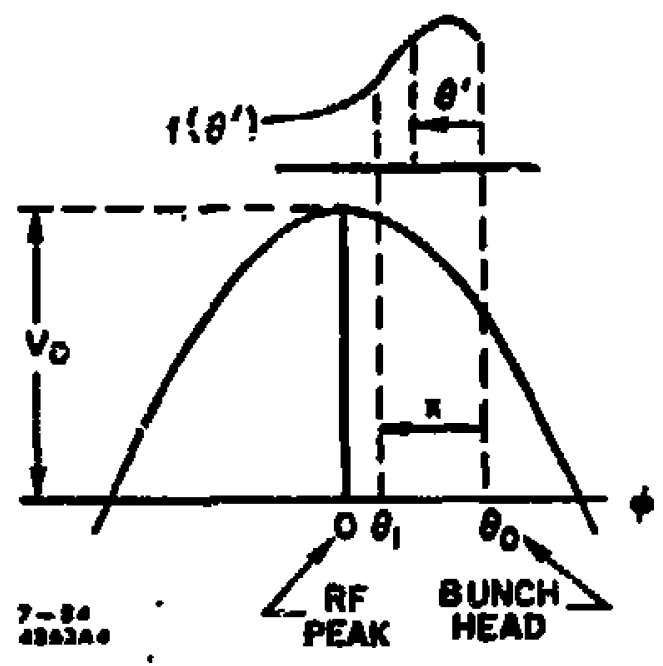

Fig. 2. Definitions of phase angles showing position of bunch with respect to accelerating wave. The charge distribution is $f\left(\theta^{\prime}\right)$ and the maximum energy gain is $V_{0}$. 
which is a Volterra integral equation of the second kind. This equation ean be solved digitally through a multi-step method using Day's starting procedure in conjunction with Simpson's rule and the three-eighth rule. The wake function can be fitted with a polynomial so as to be represented by an analytical expression.

Figures 3 and 4 give results for several examples. These examples ware all worked out for a no-load edergy $V_{0}$ of $54.75 \mathrm{GeV}$ and an accelerator length $L$ of 960 sections, each with 86 cavities (i.e., $L=2880 \mathrm{~m}, N=82560$ ). The value of $V_{0}$ was chosen so as to yield a lnal beam energy just over $50 \mathrm{GeV}$. Figure 3 shows five different bunch shapes with the corresponding $\theta_{0}$ 's (positions of the bead with respect to the wave) required to give essentially zero energy spread. The head of the bunch is on the left (zero-abscissa) and the tail defined as the point where an integrated charge of $5 \times 10^{10} e$ is reached, is at the abscissa corresponding to the letter " $T$ " on each curve. An interesting aspect of these curves is that if the hunches are extended beyond the ${ }^{~ "} T^{*}$ points as shown, the energy spread continues to be zero even though tbe sharge in the extended bunch is greater than $5 \times 10^{10} \mathrm{e}$. The end points on the individual curves give the limits of how lar one can go. Note that the shapes of the curves with $\theta_{0}=26^{\circ}$ and $20^{\circ}$ are not too "physical" in the sense that they are not likely to be obtained from a straightforward injector or damping ring. On the other hand, the $\theta_{0}=15^{\circ}$ and $14^{\circ}$ cases are more symmetrical and more likely to be realizable. The curve for $\theta_{0}=13^{\circ}$ has no $T$ because the integral under it does not quite reach $5 \times 10^{10}$ particles: its charge is $4.9 \times 10^{10} \mathrm{e}$. Figure 4 gives the respective energies of the bunches of Fig. 3 (except for the $\theta_{0}=13^{\circ}$ case) as a function of angular position. The slight curvature, i.e., deviation from perfect flatness, is real but is believed to be due to an accumulated error in the computation which causes the bunch shapes to be slightly off.

Table 1 gives a summary of the average edergies $(E)$ and spectral qualities [($E_{\text {max }}-$ $\left.E_{\min }\right) / E$ and $\left.\sigma_{E} / E\right]$ for the cases shown in Figs. 3 and 4. The definitions of $E$ and $\sigma_{E}$ are:

$$
\begin{gathered}
E=\frac{\int E(\theta) n(\theta) d \theta}{\int n(\theta) d \theta} \\
\sigma_{E}=\left[\frac{\int(E(\theta)-E)^{2} n(\theta) d \theta}{\int n(\theta) d \theta}\right]^{\frac{1}{2}}
\end{gathered}
$$




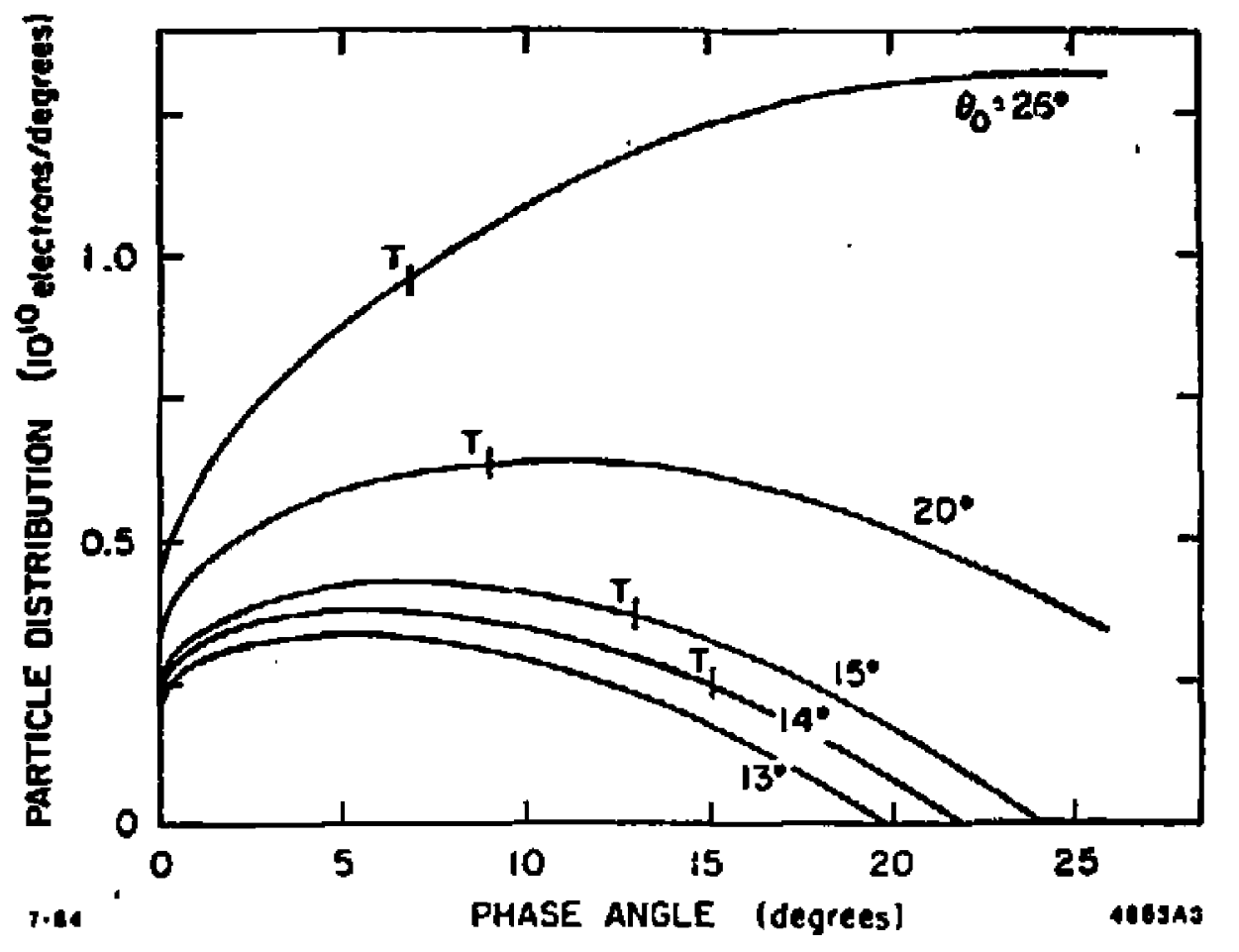

Fig. 3. Bunch shape, i.e., particle distribution as a function of pbase angle for various values of $\theta_{0}$. The point marked " $T$ " indicates where the integrated charge in the bunch reaches $5 \times 10^{10} \mathrm{e}$. 


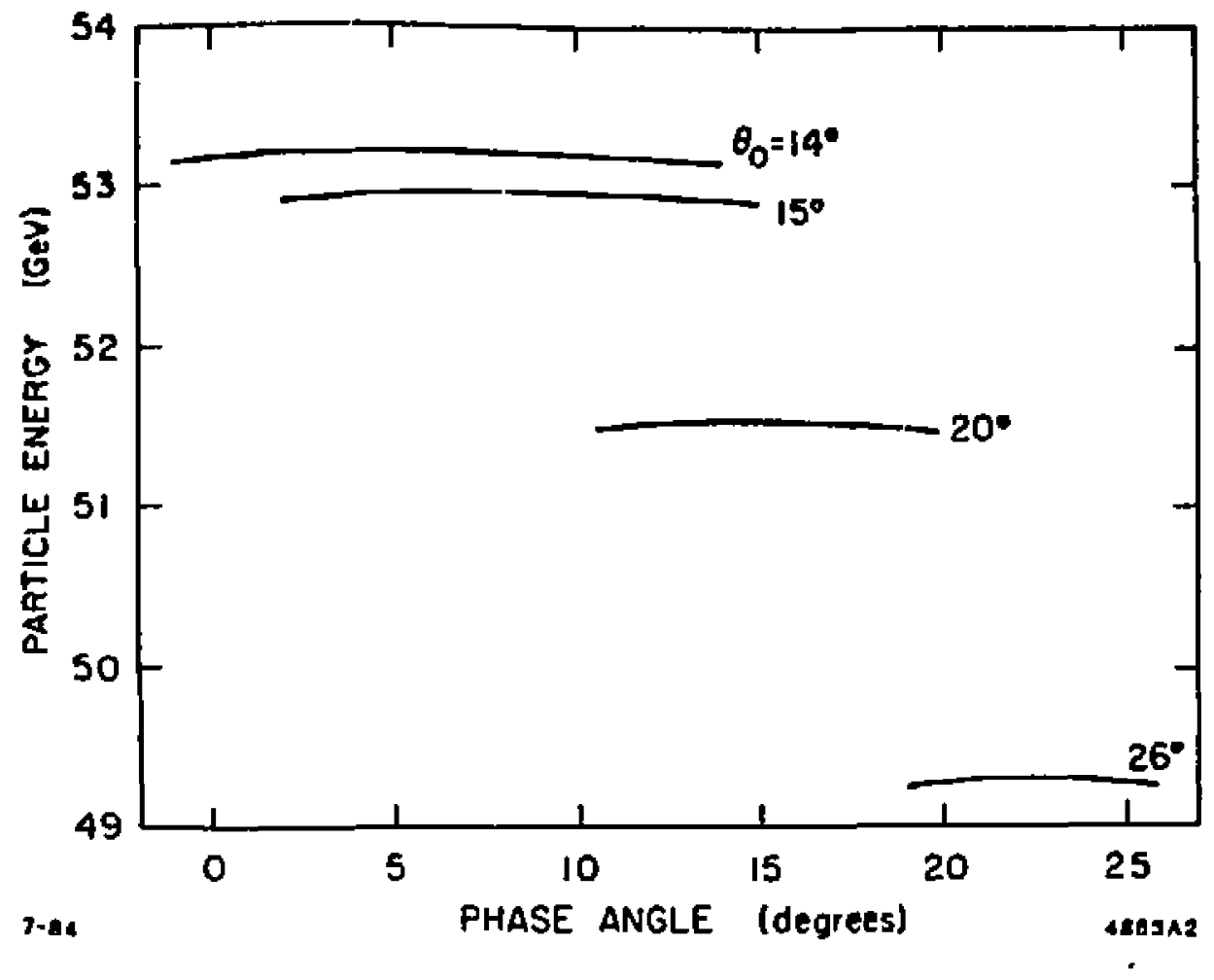

Fig. 4. Particle unergy along bunches of Fig. 3 as a function of phase angle. 
Table 1

(All cases for $5 \times 10^{10}$ particles.)

\begin{tabular}{cccc}
$\begin{array}{c}\theta_{0} \\
\text { (drgrec) }\end{array}$ & $\begin{array}{c}E \\
(G \mathrm{GV})\end{array}$ & $\begin{array}{c}\left(E_{\max }-E_{\min }\right) / E \\
(\%)\end{array}$ & $\begin{array}{c}\sigma_{E} / E \\
(\%)\end{array}$ \\
\hline 26 & -49.285 & 0.08 & 0.053 \\
20 & 51.526 & 0.135 & 0.048 \\
15 & 52.058 & 0.12 & 0.045 \\
11 & 53.196 & 0.15 & 0.049 \\
$\begin{array}{c}\text { Truncated } \\
\text { Gaussian } \\
\text { l4 }\end{array}$ & 53.233 & &
\end{tabular}

The fitth example, shown also for $\theta_{0}=14^{\circ}$, is that of a truncated Gaussian fitted to the shape of the "ideal" $\theta_{0}=14^{\circ}$ ease. It has a $\sigma_{z}$ of $8.3^{\circ}$ but is truncated at $\pm 7.3^{\circ}$. This compares with a $\sigma_{E} / E$ of $0.3 \%$ for a Gaussian bunch of total length $6 \sigma_{z}$ with a $\sigma=$ of $4^{\circ}$ and a $\theta_{0}$ of $19^{\circ}$, which is the best example used for the SLC.

Discussion

If we rewritu bq. (5) in terms of the gradient $E_{0}$ instead of the total energy $V_{0}$, the bunch shape bseomes:

$$
f(x)=\frac{E_{0} d}{w_{L}(0)} \sin \left(\theta_{0}-x\right)-\int_{0}^{x} \frac{\frac{\partial w_{L}}{\partial x}\left(x-\theta^{\prime}\right)}{w_{L}(0)} f\left(\theta^{\prime}\right) d \theta^{\prime}
$$

We sce that for a structure with a given $w_{L}(\theta)$, once the gradicnt $E_{0}$ and the angular position $\theta_{n}$ of the head are chosen, the shape is fixed by Eq. (8) and is independent of the total energy $V_{0}$ and length $L$. For a given gradient $E_{0}, f(\theta)$ starts at a bigher value as $O_{0}$ is made larger since

$$
f(0)=\frac{E_{0} d}{w_{L}(0)} \sin \theta_{0}
$$

as shown in Fig. 3. Clearly, the more eharge one wants, the bigher gradient one aeeds, of the furtlicr ahead of ercst one must place the head. 


\section{Tolerances}

To get a feeling for ellowable tolerances, it is interesting to calculate the effect of chenges in injection angle $\left(\theta_{0}\right)$ or bunch charge on $E$ sad $\sigma_{E} / E$, assuming constant buncb shape. Table 2 shows the effect of varying $\theta_{0}$ wbile keeping the total charge of the bunch equal to $5 \times 10^{10} \mathrm{e}$ in the case of the truncated Gaussian bunch discussed earlier.

Table 2

Truncated Gaussian bunch.

$$
\left(\theta_{\text {tatal }}=15^{\circ}, \sigma=8.3^{\circ}, 5 \times 10^{1 \mathrm{n}} \mathrm{e}\right)
$$

\begin{tabular}{cccc}
\hline $\begin{array}{c}\theta_{0} \\
\text { (degrees) }\end{array}$ & $\begin{array}{c}E \\
(\mathrm{GeV})\end{array}$ & $\begin{array}{c}\left(E_{\operatorname{moz}}-E_{\min }\right) / E \\
(\%)\end{array}$ & $\begin{array}{c}\sigma_{E} / E \\
(\%)\end{array}$ \\
\hline 10 & 53.52 & 1.85 & 0.54 \\
11 & 53.47 & 1.37 & 0.41 \\
12 & 53.40 & 0.94 & 0.29 \\
13 & 53.32 & 0.58 & 0.17 \\
14 & 53.22 & 0.27 & 0.086 \\
15 & 53.11 & 0.50 & 0.13 \\
16 & 52.07 & 0.88 & 0.25 \\
17 & 52.82 & 1.43 & 0.37 \\
18 & 52.66 & 1.80 & 0.49
\end{tabular}

Table 3 shows the effect of changing the bunch charge while keeping its shape and Oa constant.

Table 3

Truncated Gaussian bunch.

$$
\left(\theta_{\text {tolel }}=15^{\circ}, \quad \sigma=8.3^{\circ}, \theta_{0}=14^{\circ}\right)
$$

\begin{tabular}{cccc}
$\begin{array}{c}\text { Bunch Charge } \\
\left(\times 10^{10}\right)\end{array}$ & $\begin{array}{c}E \\
(\mathrm{GeV})\end{array}$ & $\begin{array}{c}\left(E_{\operatorname{maz}}-E_{\min }\right) / E \\
(\%)\end{array}$ & $\begin{array}{c}\sigma_{E} / E \\
(\%)\end{array}$ \\
\hline 3 & 53.63 & 1.11 & 0.35 \\
3.5 & 53.53 & 0.97 & 0.26 \\
4 & 53.43 & 0.63 & 0.19 \\
4.5 & 53.32 & 0.48 & 0.12 \\
5 & 53.22 & 0.27 & 0.086 \\
5.5 & 53.12 & 0.42 & 0.13 \\
6 & 53.02 & 0.61 & 0.20 \\
6.5 & 52.91 & 0.88 & 0.29 \\
7 & 52.81 & 1.19 & 0.37
\end{tabular}


We see Irom Table 2 that excursions away from $0_{0}=14^{\circ}$ by $\pm 1^{\circ}$ are reasondbly forgiving. The same is true for $\pm 10 \%$ excursions away from $5 \times 10^{10} e$ in Table 3 , the variations of $\sigma_{E} / E$ in both tables are close to hyperbolic.

\section{Conclunions}

We have shown in this dote that it is theoreticnlly possible to find bunch shape for the SLC which yield $5 \times 10^{10}$ or more particles within negligible eneficy spreatd at the end of the linac. As it turns out, these shapes depend only on the linute gradient and the average sagle" at which the head of the bunch is placed with raptet to the aceclerating wave, and are independent of the tots energy of length of the accelerator. Some of these theoretieal bunch shmpes are not too different frota shupee that ought to be realizable from injectors or damping tings. How to obtuin thene will be the subjeet of future work.

\section{Reforentea}

1. See for exsmple, SLAC Linenj Collider, Conceptual Design Report, BLAC wivi, pp. 17 and 117.

2. Ibid, pp. 112-116.

\section{DISCLAIMER}

This report was prepared as an account of work sponsored by an agency of the United States Government. Neither the United States Government nor any agency thereot, nor any of tbeir employees, makes any warranty. express or impliod, of assumes any legal liability or responsibility for the aceuracy, completeness, or usefulmess of any information, apparalus, product, or process disclosed, or represents that its use would not infringe privalely owned rights. Reference herein to any specijic commercial product, process, or semice hy trade name, tradernark, manufacturer, of otkerwise does not necessarily constitute or imply its endorsement. reconl. mendation, or favoriag by the United States Government or any agency thereof. The views and opinions of authors expressed berein do not necessarily state of reflect those of the United States Government or any agency thereof.

\footnotetext{
"Excursions away from this averaze angle in parts of the linse desigoed to cause Lumdat damping of the transrerse wake feld effect are of course permissible as long so overall "phase closure" to preserve the desired average $\theta_{0}$ is realized.
} 